TEXTOS DE TRADICIÓN ORAL EN LENGUA INDÍGENA 



\title{
IXQUIHUACAN Y EL ORIGEN DE AHUACATLÁN Y COALTEPEC
}

\section{IXQUIHUACAN AND THE ORIGIN OF AHUACATLÁN AND COALTEPEC}

\author{
Narración: JUAN SANTIAGO MÉNDEZ \\ Anotación y comentario: MITSUYA SASAKI
}

Resumen. Este texto de San Francisco Ixquihuacan, una comunidad nahuahablante en la Sierra occidental de Puebla, presenta un folclor local sobre el origen de dos pueblos vecinos: Ahuacatlán y Coaltepec. El narrador cuenta sobre la migración de los totonacos o totutecos al actual Ahuacatlán (y el acontecimiento religioso que ocurrió entonces) y la fundación de Coaltepec por los nahuas de Ixquihuacan para reclamar las tierras contra ellos.

PALABRAS CLAVE: náhuatl, nahua occidental, Sierra de Puebla, Ahuacatlán, historia oral.

SummarY. This text from San Francisco Ixquihuacan, a Nahuatl-speaking community in western Highland Puebla, presents local folklore on the origin of two nearby townships, Ahuacatlán y Coaltepec. The storyteller talks about the settlement of Totonacs or totutecos to the present-day Ahuacatlán (and the religious event which occurred during it) and the foundation of Coaltepec by the Nahuas who came from Ixquihuacan in order to claim the land against them.

KEYWORDS: Nahuatl, Western Nahua, Highland Puebla, Ahuacatlán, oral history.

\section{Sobre el texto}

Ixquihuacan y el origen de Abuacatlán y Coaltepec, titulado originalmente Los siete fundadores, es una historia contada por Juan Santiago Méndez, un nahuahablante de San Francisco Ixquihuacan, Sierra Norte occidental de Puebla.

El texto presentado aquí se basa en la grabación original que se realizó en el año 2015, corregida y aumentada después por el mismo narrador. A diferencia de Rebeldía de cuatreros (Santiago Méndez \& Sasaki, 2016), otra historia oral por el mismo narrador que se publicó previamente en Tlalocan, donde se reemplazaron préstamos de español con palabras nativas o más conservadoras al deseo del narrador, aquí presentamos el texto con mínimas alternaciones. 
En la traducción corrida, corregimos algunos detalles menores para que suene natural en español (p. ej., concordancia de tiempos), mientras las traducciones libres en la sección del texto glosado son más directas y reflejan los detalles gramaticales. ${ }^{1}$

Trasfondos geográficos: Ixquibuacan, Coaltepec y Ahuacatlán

El texto menciona tres comunidades en el actual municipio de Ahuacatlán, Sierra Norte occidental de Puebla: San Francisco Ixquihuacan, San Jerónimo Coaltepec y San Juan Ahuacatlán (cada pueblo es llamado localmente con el nombre del santo patrono). Las relaciones posicionales de estos tres lugares son importantes para entender el cuento.

Ahuacatlán (1 357 m s.n.m. $)^{2}$ se ubica al fondo de un valle, mientras Ixquihuacan (1540 m s.n.m.) está en la ladera y Coaltepec está entre los dos, pegado al primero. La iglesia de Ahuacatlán, cuyo origen se explica en el texto, está más arriba del centro del pueblo. Entendiendo esto, tiene sentido el cuento de que gente de Ixquihuacan bajó y fundó Coaltepec para bloquear a los totutecos, que habían migrado hasta donde está el actual Ahuacatlán.

La posición de Ahuacatlán en la Sierra también parece simbólica. Hoy en día, Ahuacatlán está literalmente en la frontera entre las regiones nahua y totonaca: la lengua totonaca es dominante al norte y al este de la cabecera, y al sur y al oeste se ubican comunidades nahuas. Aunque el pueblo de por sí es históricamente totonaco (García Martínez, 1987: 280), es ahora trilingüe en náhuatl, totonaco y español, mientras Ixquihuacan y Coaltepec son poblados totalmente nahuahablantes. La posición e historia de Ahuacatlán por lo tanto es crítica para entender la demografía histórica de la Sierra Occidental de Puebla. Para más trasfondo histórico-geográfico de esta región, véase García Martínez (1987).

\section{Historicidad}

La historicidad de la instalación de los totutecos al actual Ahuacatlán, que se cuenta en el texto, es creible. Una carta en 1925 por el Arzobispo Vera y Zuria ([1926] 1929: 180) relata

\footnotetext{
${ }^{1}$ Les debemos a los nahuahablantes de los Cruz Jiménez de Ixquihuacan la ayuda para transcribir algunas partes difíciles en la grabación para este texto. Les agradecemos también a José Aguilar Marín y Fabián Villanueva Villalobos sus consejos sobre español.

${ }^{2}$ Las cifras de altitud son del Catálogo único de claves de áreas geoestadísticas estatales, municipales y localidades (http://www.inegi.org.mx/geo/contenidos/geoestadistica/catalogoclaves.aspx). "S.n.m." = "sobre el nivel del mar".
} 


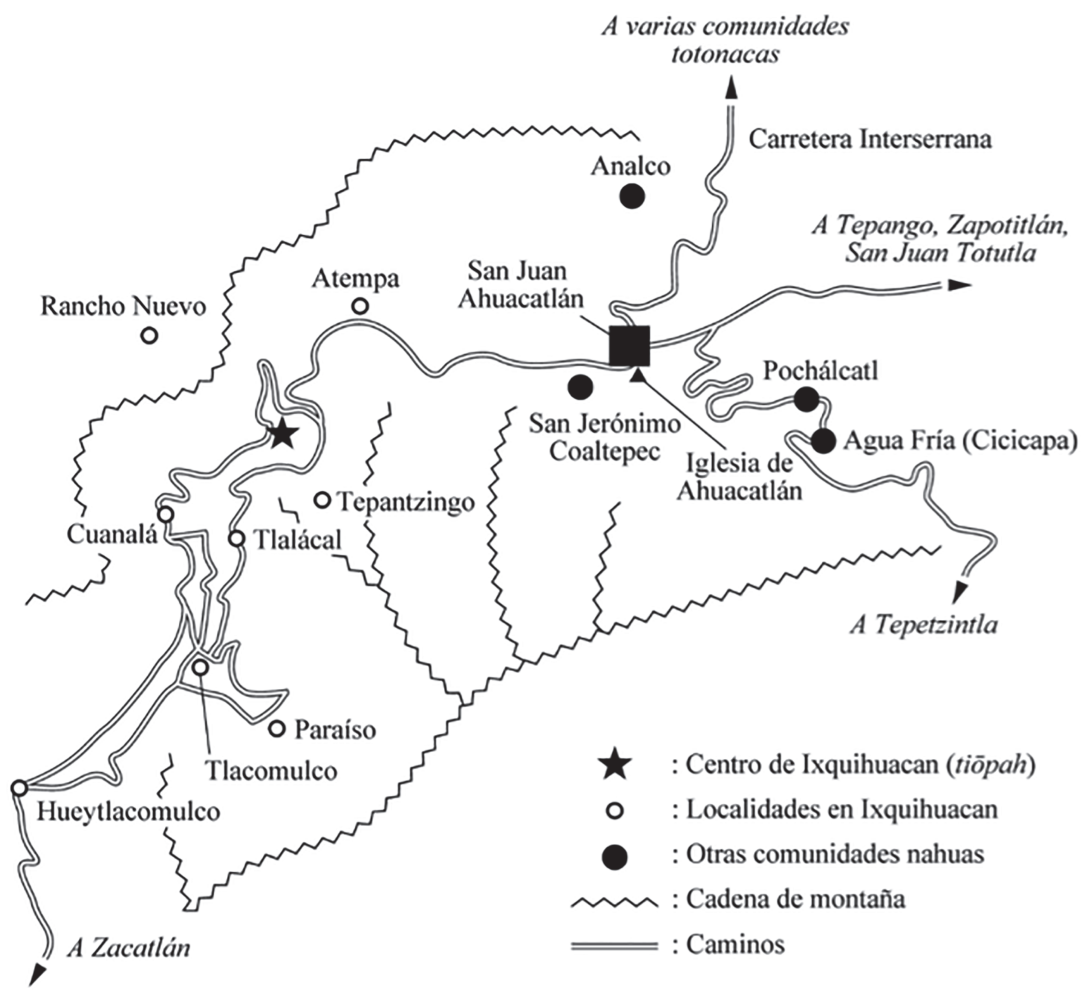

Mapa 1. Mapa actual del área Ahuacatlán-Ixquihuacan ${ }^{3}$

que: (i) había dos santos patronos de Ahuacatlán: San Miguel Arcángel y San Juan Bautista, y (ii) el segundo había sido introducido por los inmigrantes que habían venido de San Juan Totutla, huyendo de la viruela. Su comentario sugiere que esta leyenda era entonces conocida localmente.

Por otro lado, es también muy probable que, a diferencia de lo que cuenta el texto, Ahuacatlán ya hubiera sido habitado cuando ocurrió la inmigración de los totutecos. Nuestro texto relata que los totutecos fundaron Ahuacatlán alrededor del año 1705 (310 años antes de la grabación del texto original). Por otro lado, la parroquia de Ahuacatlán existía en

\footnotetext{
${ }^{3}$ Mapa 1 se basa en parte en GoogleMaps.
} 
realidad desde 1640 (Vera y Zuria, [1926] 1929: 179). Además, Torquemada (1615, III: 203) nota que el actual Ahuacatlán fue parte de la sucesión del territorio de un gobernador chichimeca y que ahí se celebraban rituales prehispánicos.

Por lo tanto, es más probable que el actual Ahuacatlán fue originalmente un poblado prehispánico. Presumiblemente, como reporta Vera y Zuria ([1926] 1929: 180), los habitantes locales (probablemente totonacos) que ya residían en el pueblo "acogieron" tanto a los migrantes totutecos como a su santo, San Juan Bautista.

Se debe señalar también que la separación de Coaltepec de Ixquihuacan contada en la leyenda es verosímil, dadas algunas semejanzas dialectales entre las variantes del náhuatl de los dos pueblos.

\section{Transcripción ${ }^{4}$}

En el náhuatl de Ixquihuacan existen cuatro vocales con el contraste de duración (/i, i:, e, e:, a, a:, o, o:/) y dieciséis consonantes nativas (/p, b, t, k, kw $, \widehat{t s}, \widehat{t} \mathrm{t}, \widehat{\mathrm{t}}, \mathrm{s}, \int, \mathrm{h}, \mathrm{m}, \mathrm{n}, \mathrm{l}, \mathrm{w}$, $\mathrm{j} /$ ). Cualquier otro fonema del español mexicano (/u, d, g, n, f, x, ${ }^{6} \mathrm{r}, \mathrm{r} /$ ) puede ocurrir en préstamos.

Aquí se utiliza el siguiente sistema de transcripción (Otros símbolos representan aproximadamente los mismos sonidos que en el AFI):

$\begin{array}{cc}\text { Transcripción } & \text { Valor fonémico } \\ c h & \overparen{/ \mathrm{t} /} \\ j & / \mathrm{x} / \\ k w & / \mathrm{k}^{\mathrm{w} /} \\ \tilde{n} & / \mathrm{n} / \\ l & / \mathrm{l} / \\ r & / \mathrm{r} / \\ r r & / \mathrm{r} /\end{array}$

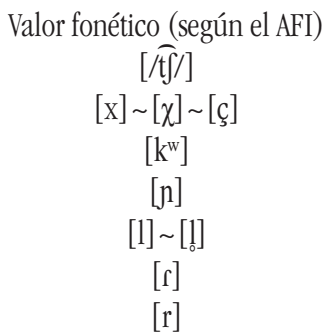

\footnotetext{
${ }^{4}$ Algunos párrafos de esta sección fueron tomados de Santiago Méndez \& Sasaki (2016: 144-145) con correcciones.

${ }^{5}$ Normalmente /u/ no existe como un fonema nativo y hablantes monolingües suelen pronunciar /u/ en español como [o] (p. ej. lōs 'luz'), mientras hablantes jóvenes tienen la distinción entre /o/ y /u/. Véase Sasaki (2014, e146).

${ }^{6}$ Aunque muchos sistemas ortográficos propuestos del náhuatl escriben $/ \mathrm{h} /$ con $\mathrm{j}$, los hablantes de Ixquihuacan comentan que /h/ de náhuatl y / $\mathrm{x}$ / de español son diferentes sonidos.
} 


$\begin{array}{ccc}t l & {[\widehat{\mathrm{tt}}]} & {[\widehat{\mathrm{t}]}]} \\ t s & / \mathrm{ts} / & {[\mathrm{ts}]} \\ x & / \mathrm{j} / & {[\delta]} \\ w & / \mathrm{w} /[\mathrm{w}] & \sim[\mathrm{w} \mathrm{w}] \sim[\mathrm{w}] \sim[\phi] \\ y & / \mathrm{j} / & {[\mathrm{j}] \sim[\mathrm{j}]} \\ \bar{a}, \bar{e}, \bar{l}, \bar{o},(\bar{u}) & / \mathrm{a}: /, / \mathrm{e}: /, / \mathrm{i}: /, / / 0: /,(/ \mathrm{u}: /) & {[\mathrm{a}:],[\mathrm{e}:],[\mathrm{i}:],[0:],[\mathrm{u}:]} \\ \hat{a}, \hat{e}, \hat{\imath}, \hat{o},(\hat{u}) & (\text { vocales acentuadas y largas) } & -\end{array}$

Especificamos la duración de vocales con un macrón ( $a$ /a/ vs. $a$ /a:/) y el acento irregular (i.e. no paroxítono) con un acento agudo $(a)$ ). Por razones tipográficas, una vocal larga e irregularmente acentuada $(\hat{a})$ se marca con un circunflejo $(\hat{a})$ en vez de un doble acento: obkôn = ohkốn [?oh'ko:n] 'asî'. Marcamos además el acento de las palabras paroxítonas en CC\# como mábtlaktl 'diez', tlámantl 'cosa' y tiôpantl 'iglesia' porque son formas excepcionales que son muy importantes en la dialectología nahua de la Sierra.

Omitimos algunos rasgos fonéticos no distintivos (p. ej. ensordecimiento de sonorantes en codas como en mākwil ['ma:kwill] 'cinco' u oclusiva glotal no fonemática como en yalwa ['jalwa?] 'ayer' y ompa ['?ompa?] 'ahî').

Los préstamos del español se representan conforme su pronunciación actual en náhuatl o en cursivas de acuerdo con la ortografía española. En el primer caso, semivocales (como $i$ en tiempo) se escriben con $y$ o $w$ (tyēmpoh).

\section{Notas dialectológicas}

El narrador Juan Santiago Méndez, nacido en Ixquihuacan en 1944, es un hablante nativo del náhuatl local del pueblo; es bilingüe en náhuatl y español.

Su variante pertenece a lo que se designa como "náhuatl de Zacatlán, Ahuacatlán y Tepetzintla" (código IS0 639-3: nbi) en Ethnologue (Eberhard et al., 2019) y como "náhuatl de la Sierra oeste de Puebla" en el catálogo del INALI (INALI 2009, 123-124). Es una variante central-occidental según el marco moderno de, entre otros, Pharao Hansen (2014).

Aunque Ixquihuacan se ubica en la Sierra Norte de Puebla, no se debe confundir con el llamado "náhuatl de la Sierra de Puebla", que se refiere normalmente al náhuat(l) del área Zacapoaxtla-Cuetzalan (código ISO 639-3: azz), que se clasifica como nahua oriental. Véase también Sasaki $(2014,2015)$ y los comentarios en Santiago Méndez \& Sasaki (2016) para más detalles. 
Los rasgos importantes del náhuatl de Ixquihuacan incluyen:

(i) gramaticalización de la partícula *in al bona fide artículo definido $n$;

(ii) uso de ìtich/îch (<*ītech) como una preposición locativa general;

(iii) elevación vocal *̌e > i (*tepētl 'cerro' > tipētl) excepto antes de $b$;

(iv) desaparición del sufijo absolutivo *-tli/*-li en temas de más de una sílaba ("kokolis-tli 'enfermedad' > kokolis);

(v) degeminación ("nikimmaka 'se lo doy (a ellos)' > nikimaka);

(vi) fusión de $V n \#$ y $V b \#$ cuando la $V$ es átona ( nikab);

(vii) descenso vocal $i>e / \_\#$ \# cuando la $h$ final no proviene de $n 0 w$ (*kimati 'lo saben' $>$ kimateb $) ;^{7}$

(viii) fonema nativo /b/ que reemplazó *kw idiosincrásicamente (*kwawitl > būwitl 'arbol');

(ix) elevación vocal o, $\bar{o}>u, \bar{u} / \_w V($ yuweh /jowih/ '(ellos)van', büwitl /bo:wit̂// (árbol').

Los rasgos (i)-(vi) son compartidos por la mayoría de variantes de la Sierra occidental, mientras (vii)-(ix) tienen una distribución más limitada.

Las reglas (v)-(vii) son particularmente importantes cuando los hablantes o investigadores de otras variantes de nahua traten de analizar el texto de Ixquihuacan, porque estos procesos a veces oscurecen las formas subyacentes.

${ }^{7}$ Por ejemplo, *kahkokwih 'lo levantan' se vuelve a kabkokweb mientras totahtsib 'nuestro padre; imagen del santo' no es sujeto al descenso vocal porque en la última forma la $b$ final viene de * $n$ (cf. Tenango totahtsin). 


\section{IXQUIHUACAN Y EL ORIGEN DE AHUACATLÁN Y COALTEPEC TEXTO EN NÁHUATL}

\section{Peregrinación de los totutecos}

Nikihtōs sē historia o kīn ōchānchīwkeh yalwa ya wīptla kipiya yēyi syēntoh wan máhtlaktl xiwitl.

Kwāndoh ōwalahkeh deh San Juan Totutla, ōkatka sē kokolis ompa. N jēntes (toknīwah) n ompa īch nōn pwēbloh ōmonōnōtskeh: "Tlakah ya katki nīn kokolis. Wan ittā kīn tikchīwaskeh?", porkéh kihtowah nōn tyēmpoh mach ōkatka sē descomunión ${ }^{8}$ (kokolis tlēn tlamāwa). Porkéh sē sacerdote tlātlámantl ōkilwihkeh, āmo keh ōkitlākachīwkeh, îka nōn n sacerdote ōkichīw nōn descomunión.

Ōpēwkeh pohpoliweh n toknīwah. Ōpēwkeh n kokolis. Ohkôn ōmiktoyah. Kāsih ōtlantoya n pwēbloh deh San Juan Totutla. Tōs n jēntes āmo ōkimatiyah tlēnoh kichīwaskeh. Tōs ōpēwkeh monōnōtsah: "Mejōr (kwali) ticholōskeh, tiyāskeh, tikīsaskeh deh nikah īch nīn pwēbloh, porkéh tlā āmo nikah tehwah tēchtokārōs, porkéh yōkintokāroh ok sikeh. Tōs tehwah ¿tlēnoh tikchiyah? Tōs wan parah tiyāskeh, tikwīkaskeh n toimājen (totahtsih), tikwīkaskeh n tosāntoh (totēkoh) keh San Juan". Ohkôn ōmochih. Ōmonōnōtskeh wan ōmosintilihkeh. Mīkeh ōkiyēkakeh, ōwalahkeh, ōkichīwkeh nonoh peregrinación. Ōwalahkeh, kwalikkah n īntotahtsih, San Juan Bautista.

Ōwalahkeh mīk tōnal. Mīk tōnal walnihninkeh. Wan ōehkokeh nikah Pochalkah. ${ }^{9}$ Ya āxah keh ${ }^{10}$ îtōka nōn lugār Sisikāpah. Ompa n ōehkokeh. ${ }^{11}$ Ompa n ōmosēwihkeh, ōkisēwihkeh n totahtsih San Juan. Wan nō kwalīkah n īnkampānah. Wan nōn kampānah,

\footnotetext{
${ }^{8}$ El narrador comenta que descomunión se refiere a una brujería. El uso de esta palabra para una enfermedad provocada por un sacerdote puede provenir de alguna creencia vulgarizada, que no hemos logrado especificar, que una excomunión por la iglesia causa algunas amenazas sobrenaturales.

${ }^{9}$ Este topónimo es oficialmente registrado hoy como Pochálcatl. Hasta ahora no podemos decidir cuál es la forma original porque su etimología es desconocida.

${ }^{10} \mathrm{El}$ uso de keh 'como' aquí implica probablemente que Cicicapa es un nombre alternativo o nativo (hoy el lugar se llama oficialmente Agua Fría, que es una traducción de Cicicapa (Sisikāpah) = sisik-ā-pah 'el lugar de agua fría').

${ }^{11}$ En esta variante hay dos verbos para 'llegar', ehko y absi; ebko se refiere a la llegada hacia el centro deíctico, mientras absi se usa en cualquier otro caso. Aunque en el náhuatl clásico se suele usar a'si para ambas direcciones, un dictaminador señaló que Carochi (1645: f. 62r) menciona e 'ko como una forma dialectal de "tierra caliente".
} 
kihtowah: “¿Kān tikpilōskeh n tokampānah?” Pēroh ompa ōkatka sē awakabūwitl. Īch n ìmāma katki īxtlapal wan ompa ōkitlālihkeh n īnkampānah.

Wan ompa ōkatkah sē kwali tyēmpoh. Sē mīk tōnal n ompa ōkatkah. Ompa ōkochiyah. Ompa ōmotlakwalchīwāya. Ompa ōmosēwihkeh. Pēroh yehwah āmo kimateh kānih yāskeh. Kān sā ōwalāyah. San ōweyikayāyah, abēr kānih ahsiskeh. San cholohtokeh por nōn kokolis tlēn ōmochīh n ompa San Juan Totutla.

\section{Fundación de Coaltepec}

Pēroh tlēn nikah n tehwah, nikah n San Francisco Ixquihuacan, kihtowah n tētiāchkah n San Francisco ōkinilweh mach panōskeh kachi mas nikah San Francisco.

Wan n tētiāchkah ōkinichikoh n tlākameh, siwāmeh. Ōkinsintileh wan ōkimilweh: "¿Tlēnoh tikchīwaskeh? Yōwalahkeh n totutecos. Walpanōskeh, tēchtlālkwilīskeh. Wan parah āmo tēchtlālkwilīskeh, makitakah kīn nikah chānchīwtokeh toknīwah. Mayākah mākwil o chikōmi tlākameh īwah n īnsiwāwah. Tikchihchīwaskeh sē tiôpantl kāmpa pēwi n ìtlāl n San Francisco. Abēr, ¿ākihkeh n yāskeh?" "Entōnses xiyākah, chikōmi tlākameh, parah xichānchīwatih, xikimīxtsakwilìih, parah ākmo tēchtlālkwilīskeh."

Ōkīskeh deh Cuanalá. ${ }^{12}$ Wan ōyahkeh parah San Jerónimo. Keh ${ }^{13}$ āxah ītōka n pwēbloh San Jerónimo. N ihkwāk nōn tōnal n tlāli deh San Jerónimo iāxka n San Francisco Ixquihuacan. Porkéh nōn tlāli tlami kāmpa chānchīwa n difunto Don Máquino León. Kāmpa chānchīwa tlami n lindēros deh San Juan wan San Francisco.

İka nōn, kihtowa nikah n tētiāchkah: "Machānchīwatih ompa, makimīxtsakwilīith nōn totutecos, porkéh ya walahtokeh wan tēchtlālkwilīskeh." Entōnses ohkôn ōkimatiyah nikah tlēn deh San Francisco mach kintlālkwilīskeh. Wan yeh āmo.

\section{Fundación de Abuacatlán}

$\mathrm{N}$ ompa yehwah nōtēwah nō monōnōtstokeh n totutecos. Ompa kateh n ompa n Sisikāpah. Yehwah nō monōnōtstokeh. Yehwah āmo kipiyah kānih ya ahsiskeh. San yuweh, san yuweh, san yuweh. Pēroh kihtowah: "Sā tiyāskeh".

\footnotetext{
${ }^{12}$ Cuanalá es una localidad en Ixquihuacan; véase el mapa.

${ }^{13}$ Este keh también se trata de un topónimo alternativo; véase nota 10.
} 
Yōmonōnōtskeh ya yuweh. Yōmonōnōtskeh ya kānah n īnsāntoh parah ya kolīnīskeh, parah ya kwīkaskeh. mo kolīniah. mo wileh kahkokweh. Kachi simi yōitiyak. Yōitiyak nōn sāntoh, San Juan; yōitiyak. Tōs kihtowah: “'Tlēka ya ihkîn ōmochīw? ¿Tlēka ya ākmo wili tikahkokweh?"

Wan de repente, ākih kwāndoh kochi, īch n ītēmik kikohkochita keh nīn San Juan, n īmpatrôn, kiniki ompa mokāwas, āmo kiniki makwīkakah. Tōs yehwātl nōn tlākatl ōkinōnōts n îkcompañērohwah: "Neh ōnikitak ihkinih. Mach nikah mokāwas n topatrôn, San Juan. Tlakah mach īwah yōmonōnōts n San Miguel."

Entōnses kihtowah mach ompa $n$ ōkichihchīwaskiyah yeh $n$ īkapīyah, tōs yōkihtoh $n$ San Juan: "neh ākmo niyās". Wan entōnses yōmonōnōtskeh, kihtowah: "Bwēnoh, pos entōnses ākmo tiyāskeh; nikah timokāwaskeh." Ompa ōkitimowihkeh. Ōkichīwaskiyah n tiôpantl ompa n Sisikāpah. Pēroh āmo ompa n ōmochīw. San ōkitimowihkeh parah tlatsīntlah, āxah kāmpa katki n tiôpantl San Juan Bautista Ahuacatlán. Entōnses ya ompa ōmokah.

Wan kwāndoh ōkahkokwkeh nōn īnsāntoh, entōnses, yōkahkokwkeh kwali, ākmo itik. Yōkolīnihkeh. Ya kwali ōkitimowihkeh parah tlatsīntlah, kāmpa katki n āxah.

\section{Ixquihuacan y Coaltepec}

Entōnses ohkôn kihtowah īch n historia.

Wan nōn tyēmpoh, tikmomakah kwēntah n ōmochihchih n tiôpantl San Juan Ahuacatlán kipiya trescientos diez años (yēyi syēntoh wan máhtlaktl xiwitl). Tōs nikah San Francisco kipiya kachi mās xiwitl. Kachi mās xiwitl n kipiya nikah. Kipiya kēmeh sē mīl īwah mākwil syēntoh wan ōmi pūwal xiwitl nikah n tiôpantl n San Francisco.

Tōs kwāndoh ōwalahkeh nōn totutecos, nikah yōchānchīwtoyah n toknīwah. Yōkatkah tlākameh. Entōnses īpah tiyuweh. xah nonoh nōn chikōmi tlākameh kinwīkah n īnsiwāwah wan n ompa ōkipixkeh īmpilwah, n ompa īch nōn lugār kāmpa ōkimīxtsakwilìtoh n totutecos.

Yōmoweyilihkeh n yēyi syēntoh xiwitl. Yōmoweyilihkeh aorītah. Yōmochih sē pwēbloh, keh āxah San Jerónimo Coaltepec. Yeh nōn n historia. 


\section{IXQUIHUACAN Y EL ORIGEN DE AHUACATLÁN Y COALTEPEC TRADUCCIÓN ESPAÑOLA}

\section{Peregrinación de los totutecos}

Contaré una historia, o cómo se instalaron en el pasado, hace 310 años.

Cuando llegaron de San Juan Totutla, había una enfermedad. Entonces la gente de ese pueblo se dijo: "Ya hay esta enfermedad. Y ¿qué vamos a hacer?", porque dicen que en ese tiempo había una descomunión (una enfermedad que contagia). Porque a un sacerdote le dijeron varios insultos, pensó que no lo respetaron; por eso el sacerdote hizo esa descomunión.

Empezó a fallecer gente. Empezó la enfermedad. Así estaban muriendo. Casi se estaba extinguiendo el pueblo de San Juan Totutla. Entonces la gente no sabía qué hacer. Entonces empezaron a decirse: "Hay que huir, hay que irnos, hay que salir de aquí, de este pueblo, porque si no, nos tocará aquí, porque ya les tocó a algunos. Entonces nosotros ¿qué esperamos? Y entonces, para irnos, llevemos la imagen, llevemos a nuestro santo, San Juan". Así se hizo. Se hablaron y se juntaron. Muchos estuvieron de acuerdo, viajaron hacia aquí, hicieron esa peregrinación. Viajaron hacia aquí y trajeron a su santo, San Juan Bautista.

Muchos días viajaron hacia aquí. Muchos días caminaron hacia aquí. Y llegaron a Pochálcatl [que está cerca de] aquí. Hoy en día ese lugar se llama Cicicapa. Ahí llegaron. Ahí se establecieron e instalaron al santo, San Juan. Y también llevaban su campana. Y [sobre] esa campana, se preguntaron: “Dónde colgaremos nuestra campana?” Entonces había un árbol de aguacate. Entre sus ramas había una [rama] plana, y ahí pusieron la campana.

Y ahí estuvieron mucho tiempo. Estuvieron ahí muchos días. Ahí dormían. Ahí cocinaban. Ahí se establecieron. Pero ellos no sabían a dónde ir. Llegaron a muchos lados. Sólo viajaron sin rumbo, para ver a dónde llegarían. Sólo estaban huyendo de esa enfermedad que ocurrió en San Juan Totutla.

\section{Fundación de Coaltepec}

Pero [por parte de] nosotros de aquí, San Francisco Ixquihuacan, dicen que el presidente de San Francisco pensó que [los totutecos] pasarían más hacia aquí, San Francisco.

Y el presidente reunió a los hombres y mujeres. Los juntó y les dijo: "¿Qué haremos? Ya vinieron los totutecos. Pasarán hacia aquí y tomarán nuestras tierras. Y para que no tomen 
nuestras tierras, que vean cómo está viviendo la gente aquí. Que vayan cinco o siete hombres y sus esposas. Haremos una iglesia donde empiezan las tierras de San Francisco. A ver, ¿quiénes irán?" "Entonces váyanse, [ustedes] siete hombres, para ir a vivir y obstruirlos para que nunca más tomen nuestras tierras".

Salieron de Cuanalá. Y fueron a San Jerónimo. Hoy el pueblo se llama San Jerónimo. En ese día la tierra de San Jerónimo era [la tierra] de San Francisco Ixquihuacan. Porque esa tierra termina donde vivía el difunto Don Máquino León. Donde vivía terminan los linderos de San Juan y San Francisco.

Por eso, dice el presidente de aquí: "Que vayan a vivir ahí, para obstruir a esos totutecos, porque ya están viniendo y tomando nuestras tierras". Entonces así pensaron los de aquí San Francisco Ixquihuacan que les tomarían la tierra. En realidad no es verdad.

\section{Fundación de Abuacatlán}

Y ahí también se hablaban los totutecos. Están ahí en Cicicapa.

Ellos también se hablaban. Ellos no sabían a dónde llegar. Sólo viajaban, viajaban, viajaban. Y ya dijeron: "Ya vámonos".

Después de que se habían hablado, se fueron. Después de que se habían hablado agarraron a su santo para moverlo, para llevárselo. No lo [pudieron] mover. No lo pudieron levantar. Ya se hizo mucho más pesado. Ya se hizo pesado ese santo, San Juan; ya se hizo pesado. Entonces dijeron: “¿Por qué pasó así? ¿Por qué no lo podemos levantar nunca más?"

Y de repente, alguien, cuando dormía, vio en su sueño que el mismo San Juan, su patrono, quería quedarse ahí, y que no quería que se lo llevaran. Entonces ese hombre habló a sus compañeros: "Yo vi tal o cual. Nuestro patrono, San Juan, quiere quedarse aquí. De hecho, San Miguel se había hablado con él". ${ }^{14}$

Entonces dicen que iban a hacer su capilla [de San Juan], y entonces San Juan ha dicho: "No me iré nunca más". Y entonces después de que se habían hablado, dijeron: "Bueno, pues entonces no viajaremos nunca más; nos quedaremos aquî́. Ahí lo bajaron [al santo]. Iban a hacer la iglesia ahí en Cicicapa. Pero no se hizo ahí. Sólo lo bajaron hasta abajo, donde hoy está la iglesia de San Juan Bautista Ahuacatán. Entonces ya se quedaron ahí.

Y cuando [trataron de] levantar a su santo, entonces, ya lo [pudieron] levantar fácilmente, no [fue] pesado. Lo movieron. Ya lo pudieron bajar para abajo, donde está hoy.

\footnotetext{
${ }^{14}$ El narrador comenta que San Juan estaba hablando con San Miguel Arcángel aquí porque Ahuacatlán fue originalmente "San Miguel Ahuacatlán". Éste es consistente con la relación de Vera y Zuria ([1926] 1929: 180); véase "Historicidad" más arriba.
} 


\section{Ixquihuacan y Coaltepec}

Entonces así se cuenta en la historia.

Y [sobre] ese tiempo, nos damos cuenta de que hicieron la iglesia de San Juan Ahuacatlán hace 310 años. Por lo tanto, aquí San Francisco tiene más años. Más años tiene aquí. Tiene alrededor de 1540 años ${ }^{15}$ la iglesia de aquí San Francisco.

Entonces cuando llegaron los totutecos, ya vivía la gente aquí. ${ }^{16}$ Ya había hombres. Ahí fuimos. Ahora esos siete hombres se llevaron a sus esposas y ahí tuvieron niños, ahí donde obstruyeron a los totutecos.

Ya [sus hogares] han aumentado en estos trescientos años. Ya han aumentado ahorita. Ya se ha hecho un pueblo, que se llama ahora San Jerónimo Coaltepec. Eso es la historia.

${ }^{15}$ Aparentemente el narrador confundió el año de la fundación con el tiempo que ha pasado desde eso.

${ }^{16}$ Esta frase no se debe confundir con la conclusión de la sección Historicidad que Ahuacatlán ya era poblado en el tiempo de la llegada de los totutecos. Como el narrador es de Ixquihuacan, siempre habla del punto de vista de Ixquihuacan. 


\section{IXQUIHUACAN Y EL ORIGEN DE AHUACATLÁN Y COALTEPEC TEXTO GLOSADO}

Nikihtōs sē historia o kīn ōchānchīwkeh yalwa ya wīptla kipiya yēyi syēntoh wan máhtlaktl xiwitl.

ni-k-ihtō-s Sē istōryah $\quad 0$ kīn $\quad \overline{0}$-chān-chīw-keh yalwa ya wīptla

1SG.S-3SG.0-decir-FuT uno histori o cómo PST-hogar-hacer.PRT-PL.S ayer ya antier

ki-piya yēyi syēntoh wan máhtlaktl xiwi-tl

3SG.0-tener tres ciento y cinco año-ABS.SG

Contaré una historia, o cómo se instalaron en el pasado, hace 310 años.

Kwāndoh ōwalahkeh deh San Juan Totutla, ōkatka sē kokolis ompa.

kwāndoh ō-walah-keh deh Sān Jwān Totūtlah ō-katka sē kokolis ompa cuando PST-venir.PRT-PL.S de San Juan Totutla PST-estar.PRT uno enfermedad ahí Cuando vinieron de San Juan Totutla, habia una enfermedad abí.

N jēntes n ompa īch nōn pwēbloh ōmonōnōtskeh:

$n$ jēnte-s n ompa ī(ti)ch nōn pwēbloh ō-mo-nō nōts-keh

ar gente-PL ART ahí en ese pueblo PST-REFL-ITER llamar.PRT-PL.S

Entonces la gente de abi en ese pueblo se habló:

"Tlakah ya katki nīn kokolis."

Tlakah ya katki nīn kokolis

¡ah, sí $!^{17}$ ya estar este enfermedad

"Ya hay esta enfermedad."

"Wan ¿ttā kīn tikchīwaskeh?"

wan tlā kīn ti-k-chīwa-s-keh
y si cómo 1PL.S-3SG.0-hacer-FuT-PL.S
"Y ¿qué vamos a hacer?"

Porkéh kihtowah nōn tyēmpoh mach ōkatka sē descomunión.

porkéh k-ihtowa-h nōn tyēmpoh mach ō-katka sē deskomunyôn porque 3SG.0-decir-PL.S ese tiempo según ${ }^{18}$ PST-estar.PRT uno descomunión Porque dicen que en ese tiempo babía una "descomunión".

${ }^{17}$ Tlakah, como tlaka' en el náhuatl clásico, introduce una oración que describe un hecho o acontecimiento inesperado.

${ }^{18} \mathrm{Mach}$ introduce una oración reportativa (i.e. que describe algo que no es una experiencia directa). 
Porkéh sē sacerdote tlātlámantl ōkilwihkeh, āmo keh ōkitlākachīwkeh; porkéh sē saserdōteh tlā fláman-tl ō-k-ilwih-keh āmo keh porque uno sacerdote DISTR COSa-ABS.SG PST-3SG.0-decir.PRT-PL.S NEG que

ō-ki-tlāka-chīw-keh

PST-3SG.o-hombre-hacer.PRT-PL.S

Porque a un sacerdote dijeron varias cosas [malas], [pensó] que no lo respetaron,

īka nōn n sacerdote ōkichīw nōn descomunión.

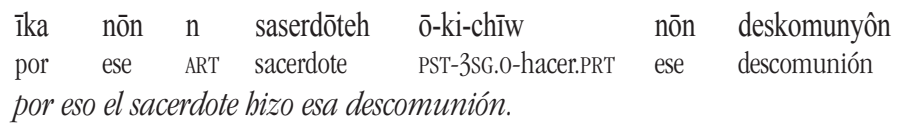

Ōpēwkeh pohpoliweh n toknīwah.

ō-pêw-keh $\quad$ poh poliwi-h $\quad \mathrm{n} \quad$ to-knīw-wān

PST-empezar.PRT-PL.S PLAC faltar-PL.S ART 1PL.P-hermano-POS.PL

Empezó a fallecer la gente.

Ōpēwkeh n kokolis.

o-pēw-keh n kokolis

PST-empezar.PRT-PL.S ART enfermedad

Empezó la enfermedad.

Ohkôn ōmiktoyah.

ohkôn ō-mik-to-ya-h

así PST-Morii-PROG-IMPF-PL.S

Así estaban muriendo.

Kāsih ōtlantoya n pwēbloh deh San Juan Totutla.

$\begin{array}{llllllll}\text { kāsih } & \overline{0} \text {-tlam-to-ya } & \mathrm{n} & \text { pwēbloh } & \text { deh } & \text { Sān } & \text { Jwān } & \text { Totütlah } \\ \text { casi } & \text { PST-terminar-PROG-IMPF } & \begin{array}{l}\text { ART } \\ \text { pueblo }\end{array} & \text { de } & \text { San } & \text { Juan } & \text { Totutla } \\ \text { Casi se estaba extinguiendo el pueblo de San Juan Totutla. } & & \end{array}$

Tōs n jēntes āmo ōkimatiyah tlēnoh kichīwaskeh.

$\begin{array}{lllllll}\text { tōs } & \mathrm{n} & \text { jēnte-s } & \bar{a} \text { amo } & \overline{0} \text {-ki-mati-ya-h } & \text { tleh-nōn }{ }^{19} & \text { ki-chīwa-s-keh } \\ \text { entonces } & \text { ART } & \text { gente-PL } & \text { NEG } & \text { PST-3SG.0-saber-IMPF-PL.S } & \text { qué-ese } & \text { 3sG.o-hacer-FuT-PL.S }\end{array}$ Entonces la gente no sabia qué bacer.

${ }^{19}$ Aquí el interrogativo tlēnoh se analiza tentativamente como la combinación de tleh '¿qué?' + nōn 'ese'. El cambio de eh\#n a èn es regular: tleh $\mathrm{n}>$ ttèn; yeh $n>$ yèn; deh $n>$ dèn. 
Tōs ōpēwkeh monōnōtsah:
tōs
ō-pēw-keh
mo-nō nōtsa-h
entonces PST-empezar.PRT-PL.S
REFL-ITER llamar-PL.S

Entonces empezaron a decirse:

"Mejōr ticholōskeh, tiyāskeh, tikīsaskeh deh nikah īch nīn pwēbloh," mejōr ti-cholō-s-keh ti-yā-s-keh ti-kīsa-s-keh deh nikān ī(ti)ch nīn pwēbloh mejor 1PL.S-huir-fut-PL.S 1PL.S-ir-Fut-PL.S 1PL.S-salir-Fut-PL.S de aquí en este pueblo "Hay que buir, bay que irnos, bay que salir de aqui, de este pueblo,"

"porkéh tlā āmo nikah tehwah tēchtokārōs, porkéh yōkintokāroh ok sikeh." porkéh tlā āmo nikān tehwān tēch-tokār-ō-s porkéh $\mathrm{y}=\overline{0}-$ kim-tokār-oh porque si NEG aquí 1PL 1PL.o-tocar-LV-FuT porque ya=PST-3PL.0-tocar-LV.PRT

ok sik-ēn

aún alguno-PL

"porque si no, nos tocará aquí, porque ya les tocó a algunos."

"Tōs tehwah ¿ttēnoh tikchiyah?"
tōs tehwān tleh-nōn ti-k-chiya-h
entonces 1PL qué-ese 1PL.S-3SG.0-esperar-PL.S
"Entonces nosotros ¿qué esperamos?"

"Tōs wan parah tiyāskeh, tikwīkaskeh n toimājen, tikwīkaskeh n tosāntoh keh San Juan."

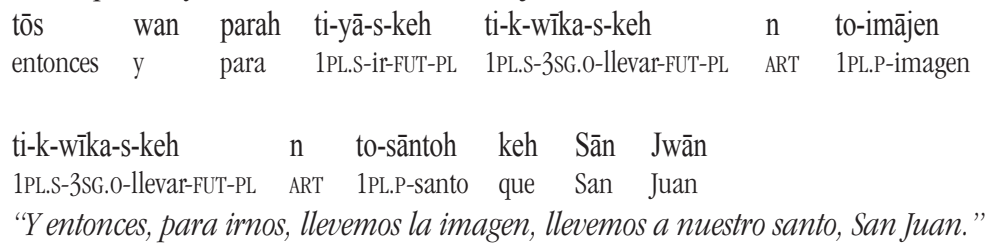

Ohkôn ōmochih.
ohkôn ̄-mo-chīw
así PST-REFL-hacer.PRT

Asíse bizo.

Ōmonōnōtskeh wan ōmosintilihkeh.

$\begin{array}{lll}\overline{0}-\text {-mo-nō } \sim \text { nōts-keh } & \text { wan } & \overline{0} \text {-mo-sintilih-keh } \\ \text { PST-REFL-ITER llamar.PRT-PL.S } & \text { y } & \text { PST-REFL-juntar.PRT-PL.S } \\ \text { Se hablaron y se juntaron. } & & \end{array}$


Mīkeh ōkiyēkakeh, ōwalahkeh, ōkichīwkeh nonoh peregrinación.

$\begin{array}{lllll}\text { mīk-ēn } & \overline{0}-k i \text {-yēk-kak-keh } & \overline{0} \text {-walah-keh } & \overline{0} \text {-ki-chīw-keh } & \text { nonōn } \\ \text { mucho-PL } & \text { PST-3SG.0-bien-escuchar.PRT-PL.S } & \text { PST-venir.PRT-PL.S } & \text { PST-3SG.0-hacer-PL.S } & \text { ese }\end{array}$

peregrinasyôn

peregrinación

Muchos estuvieron de acuerdo, viajaron hacia aquí, hicieron esa peregrinación.

Ōwalahkeh, kwalīkah n intotahtsih, San Juan Bautista.

o-walah-keh k-walikka-h $\quad \mathrm{n} \quad$ ìm-to-tah-tsīn $\quad$ San Jwān Bawtistah

PST-venir-PRT.PL 3SG.0-ven.llegar-PL.S ART 3PL.P-1PL.P-padre-HoN San Juan Bautista

Viajaron bacia aquí trajeron a su santo, San Juan Bautista.

Ōwalahkeh mīk tōnal.

ö-walah-keh mīk tōnal

PST-venir-PRT.PL mucho día

Muchos días viajaron bacia aquí.

Mīk tōnal walnihninkeh.

mīk tōnal wal-nihnim-keh

mucho día ven-caminar.PRT-PL.S

Muchos días caminaron bacia aquí.

Wan ōehkokeh nikah Pochalkah.
wan ō-ehko-k-keh ${ }^{20}$ nikān Pochalcah
y PST-ven.llegar-PRT-PL.S aquí Pochálcatl
Y llegaron a Pochálcatl [que está cerca de] aquí.

Ya āxah keh ītōka nōn lugār Sisikāpah.

ya āxān keh ì-tōkā nōn lugār $\quad$ Sisikāpah
ya ahora que 3sG.P-nombre ese
Hoy en día ese lugar
Cicicapa
llama Cicicapa.

${ }^{20}$ Aunque -keh en ōehkokeh, -tokeh, etc. no viene diacrónicamente de la degeminación de *-k-keh sino que es el reflejo directo del protonahua *-kā-t(i) (-PRT-PL.S), aquí analizamos la terminación como -k-keh (-PRT-PL.S) de manera intencionalmente anacrónica porque es más apropiado sincrónicamente e intradialectalmente dado la degeminación regular $k k>k$ y el marcador $-k e h$ en cualquier otro entorno. Según este análisis no existe un marcador -eb en esta variante (aparte de la terminación de la forma irregular kateh 'están' y el -eh en sikeb 'algunos', nōnkeh 'esos', etc. que es subyacentemente -ēn). Para más argumentos véase Santiago Méndez \& Sasaki (2016, 151, nota 7). 
Ompa n ōehkokeh.

ompa n $\quad \overline{0}$-ehko-k-keh

ahí ART PST-ven.llegar-PRT-PL.S

Abíllegaron.

Ompa n ōmosēwihkeh, ōkisēwihkeh n totahtsih San Juan.
ompa n $\overline{0}$-mo-sēwih-keh
ö-ki-sēwih-keh
$n \quad$ to-tah-tsīn
ahí $\quad{ }_{\text {ART }}$
PST-3SG.0-descansar.PRT-PL.S
ART 1PL.P-padre-HON
San Jwān
San Juan
Abíse establecieron e instalaron al santo, San Juan.

Wan nō kwalīkah n īnkampānah.

$\begin{array}{lllll}\text { wan } \quad \text { nō } & \text { k-walīka-h } & \mathrm{n} & \text { im-kampānah } \\ \text { y } & \text { también } & \text { 3SG.0-ven.llevar-PL.S } & \text { ART } & \text { 3PL.P-campana } \\ \text { Y también llevan su campana. } & & \end{array}$

Wan nōn kampānah, kihtowah:

wan nōn kampānah k-ihtowa-h
y ese campana 3sG.o-decir-PL.S
$Y$ [sobre] esa campana, dicen:

“Kān tikpilōskeh n tokampānah?”
kān ti-k-pilō-s-keh n to-kampānah
dónde 1PL.S-3SG.0-colgar-FuT-PL.S ART 1PL.P-campana
"Dónde colgaremos nuestra campana?"

Pēroh ompa ōkatka sē awakabūwitl.

\begin{tabular}{llll} 
pēroh ompa & $\overline{0}$-katka & \multicolumn{1}{c}{ sē } & awaka-bōwi-tl \\
pero ahí & PST-estar.PRT & uno & aguacate-árbol-ABS.SG \\
Entonces babía & un árbol de aguacate.
\end{tabular}

Īch n īmāma katki īxtlapal wan ompa ōkitlālihkeh n īnkampānah.
$\bar{i}($ ti)ch n $\quad \overline{1}$-mā $\sim m a \bar{a} \quad$ katki ixtlapal wan ompa ō-ki-tlālih-keh
en ART 3SG.P-DISTR mano estar horizontal y ahí PST-35G.0-poner.PRT-PL.S
n ìm-kampānah
ART 3PL.P-campana
Entre sus ramas había una [rama] plana, y ahípusieron su campana. 
Wan ompa ōkatkah sē kwali tyēmpoh.

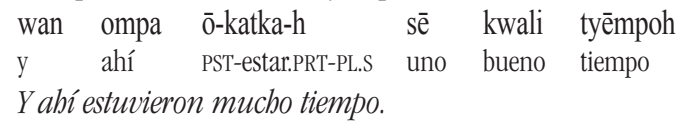

Sē mīk tōnal n ompa ōkatkah.
sē mīk tōnal $\mathrm{n}$
ompa ō-katka-h
uno mucho día ART ahí PST-estar.PRT-PL

Estuvieron abí como muchos días.

Ompa ōkochiyah. Ompa ōmotlakwalchīwāya. Ompa ōmosēwihkeh.
ompa $\overline{0}$-kochi-ya-h ompa ō-mo-tlakwal-chīwa-ya-h ompa
ahí PST-dormir-IMPF-PL.S ahí PST-REFL-Comida-hacer-IMPF-PL.S ahí
ō-mo-sēwih-keh
PST-REFL-descansar.PRT-PL.S
Abi dormian. Abi cocinaban. Abi se establecieron.

Pēroh yehwah āmo kimateh kānih yāskeh.
pēroh yehwān āmo ki-mati-h
kānin yā-s-keh
pero 3PL
NEG 3SG.0-saber-PL.
dónde ir-FUT-PL.S
Pero ellos no saben a dónde ir.

Kān sā $\overline{2}^{21}$ ōwalāyah.
kān sā
ō-walā-ya-h
dónde ya.solo $0^{22}$
PST-Venir-IMPF-PL.S
Vinieron a muchos lados.

San ōweyikayāyah, abēr kānih ahsiskeh.
san o-weyika-yā-ya-h ${ }^{23}$ abēr kānih ahsi-s-keh
sólo PST-amplio-ir-IMPF-PL.S a.ver dónde llegar-FuT-PL.S
Sólo viajaron sin rumbo, para ver a dónde llegarían.

${ }^{21}$ Kān sā es un modismo para "varios lugares" (cf. tlēn sā 'varias cosas').

${ }^{22} \mathrm{El}$ sentido general de sā 'ya solo ...' es casi igual que lo que reporta Carochi (1645: f. 110r): significa 'solo' pero tiene algún matiz temporal.

${ }^{23} \mathrm{El}$ verbo weyikayuwi significa 'ir sin rumbo'. Véase wèyikā- 'ampliamente, a gran precio' en el náhuatl clásico y tawēiya 'capacidad, amplio' en Zacapoaxtla (Key \& de Key, 1953: 10, 25, 206). 
San cholohtokeh por nōn kokolis tlēn ōmochīh n ompa San Juan Totutla.

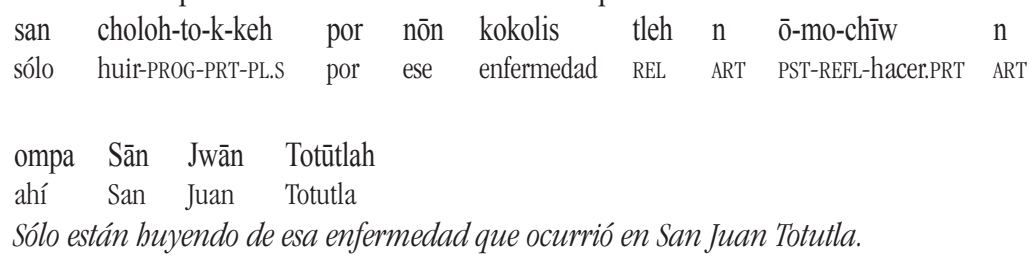

Pēroh tlēn nikah n tehwah, nikah n San Francisco Ixquihuacan, kihtowah n tētiāchkah n San Francisco ōkinilweh mach panōskeh kachi mas nikah San Francisco.

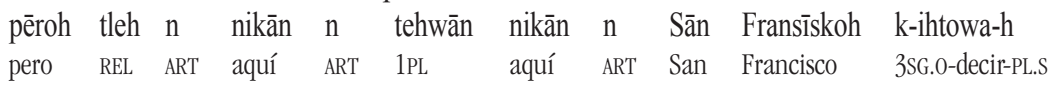

$\begin{array}{llllllll}\text { n } & \text { tē-tiāchkā-w } & n & \text { Sān } & \text { Fransīskoh } & \bar{o}-k i-n i l w i h & \text { mach } & \text { panō-s-keh } \\ \text { ART } & \text { IH.P-lí́der-POS.SG } & \text { ART } & \text { San } & \text { Francisco } & \text { PST-3SG.0-pensar.PRT } & \text { según } & \text { pasar-FUT-PL.S }\end{array}$

kachi māš ${ }^{24}$ nikān Sān Fransīskoh más más aquí San Francisco

Pero [por parte de] nosotros de aquí, San Francisco Ixquibuacan, dicen que el presidente de San Francisco pensó que [los totutecos] pasarían más hacia aquí, San Francisco.

Wan n tētiāchkah ōkimnichikoh n tlākameh, siwāmeh.

$\begin{array}{lllllll}\text { wan } & \mathrm{n} & \text { tē-tiāchkā-w } & \overline{0} \text {-kim-nichikoh } & \mathrm{n} & \text { tlāka-meh } & \text { siwā-meh } \\ \text { y } & \text { ART } & \text { IH.P-líder-POS.SG } & \text { PST-3PL.0-reunir.PRT } & \text { ART } & \text { hombre-ABS.PL } & \text { mujer-ABS.PL } \\ \text { Yel presidente reunió a los hombres y mujeres. } & & & \end{array}$

Ōkinsintileh wan ōkimilweh:

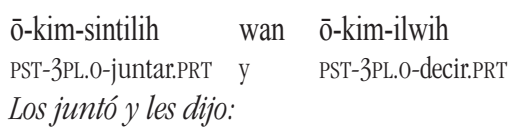

“¿Tlēnoh tikchīwaskeh?”

tleh-nōn ti-k-chīwa-s-keh

qué-ese 1PL.S-3SG.0-hacer-FuT-PL.S

"Québaremos?"

\footnotetext{
${ }^{24} \mathrm{El}$ adverbio nativo kachi (cf. náhuatl clásico ok achi) se combina opcionalmente pero muy a menudo con su contraparte española mās sin cambio de sentido. Glosamos las dos palabras como 'más'.
} 
"Yōwalahkeh n totutecos."

$\mathrm{y}=\overline{0}$-walah-keh $\quad \mathrm{n} \quad$ totutēko-s

$\mathrm{ya}=$ PST-venir.PRT-PL.S $\quad$ ART $\quad$ totuteco-PL

"Ya vinieron los totutecos."

"Walpanōskeh, tēchtlālkwilīskeh."

wal-panō-s-keh tēch-tlàl-kwi-lī-s-keh

ven-pasar-FuT-PL.S 1PL.o-tierra-tomar-APL-FUT-PL.S

"Pasarán bacia aqui y tomarán nuestras tierras."

"Wan parah āmo tēchtlālkwilīskeh, makitakah kīn nikah chānchīwtokeh toknīwah."

$\begin{array}{lllllll}\text { wan } & \text { parah } & \text { āmo } & \text { tēch-tlāl-kwi-lī-s-keh } & \text { ma-k-ita-kah } & \text { kīn } & \text { nikān } \\ \text { y } & \text { para } & \text { NEG } & \text { 1PL.o-tierra-tomar-APL-FUT-PL.S } & \text { OPT-3SG.o-ver-OPT.PL.S } & \text { cómo } & \text { aquí }\end{array}$

chān-chīw-to-k-keh to-knīw-wān

hogar-hacer-PROG-PRT-PL.S $\quad$ 1PL.P-hermano-POS.PL

"Y para que no tomen nuestras tierras, que vean cómo está viviendo la gente aquí."

"Mayākah mākwil o chikōmi tlākameh īwah n īnsiwāwah."

ma-yā-kah mākwil o chikōmi tlāka-meh ì-wān n īn-siwā-wān

OPT-ir-OPT.PL.S cinco 0 siete hombre-ABS.PL 3 3SG.P-Con ART 3SG.P-mujer-PoS.PL

"Que vayan cinco o siete hombres y sus esposas."

"Tikchihchīwaskeh sē tiôpantl kāmpa pēwi n îtlāl n San Francisco."

ti-k-chih chīwa-s-keh sē tiôpan-tl kāmpa pēwi $n$ ī-tlāl $n$

1PL.S-3SG.0-PIAC hacer-FUT-PL.S uno iglesia-ABS.SG donde empezar ART 3SG.P-tierra ART

Sān Fransisskoh

San Francisco

"Haremos una iglesia donde empiezan las tierras de San Francisco."

"Abēr, ¿ākihkeh n yāskeh?"

abēr ākihkeh n yā-s-keh

a.ver quién.PL ART ir-FUT-PL.S

"A ver, ¿quiénes irán?" 
Mâkihoh Leôn

Máquino León

Porque esa tierra termina donde vive el difunto Don Máquino León.

Kāmpa chānchīwa tlami n lindēros deh San Juan wan San Francisco.

kāmpa chān-chīwa tlami $\mathrm{n}$ lindēro-s deh Sān Jwān wan Sān Fransīskoh

donde hogar-hacer terminar ART lindero-PL de San Juan y San Francisco

Donde vive terminan los linderos de San Juan y San Francisco.

İka nōn, kihtowa nikah n têtiāchkah:

ìka nōn k-ihtowa nikān $n$ tē-tiāchkā-w

por ese 3sG.o-decir aquí ART IH.P-líder-Pos.SG

Por eso, dice el presidente de aquí:

"Machānchīwatih ompa, makimīxtsakwilītih nōn totutecos, porkéh ya walahtokeh wan tēchtlālkwilīskeh."

ma-chān-chīwa-ti-h ompa ma-kim-īx-tsakwi-li-ti-h nōn

OPT-hogar-hacer-AND.PROP-OPT.PL.S ahí OPT-3PL.0-superficie-cerrar-APL-AND.PROP-OPT.PL.S ese

totutēko-s porkéh ya walah-to-k-keh wan tēch-tlāl-kwī-s-keh

totuteco-PL porque ya venir-PROG-PRT-PL.S y 1PL.0-tierra-tomar-PUT-PL.S

"Que vayan a vivir abí, para obstruir a esos totutecos, porque ya están viniendo y tomando nuestras tierras."

Entōnses ohkôn ōkimatiyah nikah tlēn de San Francisco mach kintlālkwilīskeh.

entōnses ohkôn ō-ki-mati-ya-h nikān tleh $\mathrm{n}$ deh Sān Fransīskoh mach

entonces así PST-3SG.0-saber-IMPF.-PL.S aquí REL ART de San Francisco según

kim-tlāl-kwi-līs-keh

3PL.0-tierra-tomar-APL-PL.S

Entonces asípiensan los de aqui San Francisco Ixquihuacan, que les tomarían la tierra.

Wan yeh āmo

wan yeh āmo

y $3 \mathrm{SG} \quad \mathrm{NEG}$

$Y$ eso no es correcto. 
N ompa yehwah nōtēwah nō monōnōtstokeh $\mathrm{n}$ totutecos.

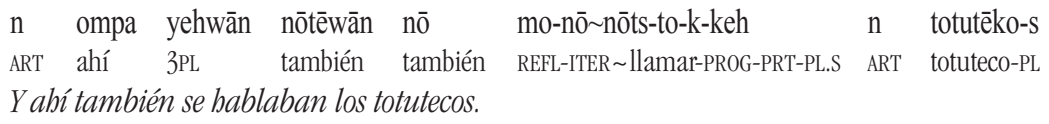

Ompa kateh n ompa n Sisikāpah.

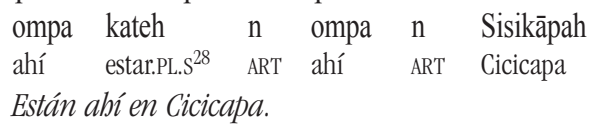

Yehwah nō monōnōtstokeh
yehwān nō mo-nō nōts-to-k-keh
3PL también REFL-TTER llamar-PROG-PRT-PL.S
Ellos también se bablaban.

Yehwah āmo kipiyah kānih ya ahsiskeh.

\begin{tabular}{|c|c|c|c|c|c|}
\hline yehwān & āmo & ki-piya-h & kānih & ya & ahsi-s-keh \\
\hline & NEG & 3SG.o-tener-PL.S & dónde & ya & llegar-FuT-PL.S \\
\hline
\end{tabular}

San yuweh, san yuweh, san yuweh.

san yowi-h san yowi-h san yowi-h

sólo ir-PL.S solo ir-PL.S solo ir-PL.S

Sólo viajan, viajan, viajan.

Pēroh kihtowah: "Sā tiyāskeh".
pēroh k-ihtowa-h sā ti-yā-s-keh
pero 3sG.0-decir-PL.S ya.solo 1PL.S-ir-FUT-PL.S
Pero dicen: "Ya irémonos."

Yōmonōnōtskeh ya yuweh.

$$
\begin{aligned}
& \text { y=̄o-mo-nō } \sim \text { nöts-keh } \quad \text { ya } \quad \text { yowi-h } \\
& \text { ya=PST-REEL-TTER } \sim \text { llamar-PL.S ya ir-PL.S } \\
& \text { Después de que se bablaron se van. }
\end{aligned}
$$

${ }^{28}$ Aunque la terminación -eh en kateh funciona obviamente como un marcador de pluralidad, glosamos esta forma sin separar morfemas porque es irregular interdialectalmente (forma esperada: *katkeb) y no reconocemos un morfema *-eh en esta variante. Véase nota 20. 
Yōmonōnōtskeh ya kānah n īnsāntoh parah ya kolīnīskeh, parah ya kwīkaskeh. y=ō-mo-nō nōts-keh ya k-āna-h ìm-sāntoh parah ya k-olinī-s-keh ya=PST-REFL-TTER $\sim$ llamar-PL.S ya 3SG.0-agarrar-PL.S 3PL.S-Santo para ya 3SG.0-mover-FUT-PL.S Después de que se hablaron abora agarran a su santo para moverlo, para llevárselo.

Āmo kolīiniah.

āmo k-olīnia-h

NEG 3SG.0-mover-PL.S

No lo mueven.

Āmo wileh kahkokweh.

āmo wili-h k-ahkokwi-h

NEG poder-PL.S 3SG.0-levantar-PL.S

No lo pueden levantar.

Kachi simi yōitiyak..

kachi simi $\mathrm{y}=\overline{0}-$-itiya-k

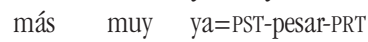

Ya se hizo mucho más pesado.

Yōitiyak nōn sāntoh, San Juan; yōitiyak.

$\mathrm{y}=\overline{0}$-itiya-k nōn sāntoh Sān $\quad J w a ̄ n ~ \quad y=\overline{0}-$-itiya-k

$\mathrm{ya}=$ PST-pesar-PRT ese santo San Juan $\mathrm{ya}=$ PST-pesar-PRT

Ya se hizo pesado ese santo, San Juan; ya se hizo pesado.

Tōs kihtowah:

tōs k-ihtowa-h

entonces 3SG.0-decir-PL.S

Entonces dicen:

“¿Tlēka ya ihkîn ōmochīw?”

tlēka ya ihkîn ō-mo-chīw

por.qué ya como.éste PST-REFL-hacer.PRT

"Por quépasó asi??"

“¿Tlēka ya ākmo wili tikahkokweh?”

tlēka ya ākmo wili ti-k-ahkokwi-h

por.qué ya ya.no.más poder 1PL.s-3SG.o-levantar-PL.S

"Por qué no lo podemos levantar nunca más?" 
Wan de repente, ākih kwāndoh kochi, īch n ìtēmik kikohkochita keh nīn San Juan, n impatrôn, kiniki ompa mokāwas, āmo kiniki makwīkakah.

wan deh rrepēnteh ākin kwāndoh kochi î(ti)ch n î-tēmik ki-koh $\sim$ koch-ita

y de repente alguien cuando dormir en ART 3SG.P-sueño 3SG.0-PIAC $\sim$ sueño-ver

keh $\mathrm{n}$ nīn Sān Jwān $\mathrm{n}$ ìm-patrôn ki-niki ompa mo-kāwa-s āmo que ART este San Juan ART 3PL.P-patrón 3SG.0-querer ahí REFL-dejar-FUT NEG

ki-niki ma-k-wīka-kān

3sG.0-querer opT-3GG.0-llevar-OPT.PL.S

$Y$ de repente, alguien, cuando duerme, ve en su sueño que este San Juan, su patrono, quiere quedarse ahi, y que no quiere que se lo lleven.

Tōs yehwātl nōn tlākatl ōkinōnōts n īkompañērohwah:
n ̇̄-kompanēroh-wān

tōs yehwātl nōn tlāka-tl o o-ki-nō nnōts

entonces 3SG ese hombre-ABS.SG PST-3SG.0-ITER Ilamar.PRT ART 3SG.P-Compañero-POS.PL

Entonces ese hombre habló a sus compañeros:

"Neh ōnikitak ihkinih."
neh $\quad \overline{0}$-ni-k-ita-k
ihkîn-nīn ${ }^{29}$
1 SG $\quad$ PST-1SG.S-3SG.0-Ver-PRT
como-éste
"Yo vi algo como éste."

"Mach nikah mokāwas n topatrôn, San Juan." mach nikān mo-kāwa-s n to-patrôn San Jwān según aquí REFL-dejar--uT ART 1PL.P-patron San Juan "Nuestro patrono, San Juan, quiere quedarse aquí."

"Tlakah mach īwah yōmonōnōts n San Miguel."

Tlakah mach ì-wān $\mathrm{y}=\overline{0}-\mathrm{mo}$-nō $\sim$ nōts $\quad \mathrm{n} \quad$ Sān Migēl ¡ah_sí! según 3SG.P-con ya=PST-REFL-TTER llamar.PRT ART San Miguel "De hecho San Miguel se habia hablado con él."

${ }^{29}$ Ihkinih 'como éste' se analiza tentativamente como ihkîn 'como éste' + nin 'éste'. 
Entōnses kihtowah mach ompa n ōkichihchīwaskiyah yeh n īkapīyah, entōnses k-ihtowa-h mach ompa $n$ o-ki-chih $\sim$ chīwa-skiya-h yeh $n$ entonces 3SG.0-decir-PL.S según ahí ART PST-3SG.0-PIAC hacer-CTRF-PL.S 3 3SG ART

i-kapiyah

3sG.P-capilla

Entonces dice que él iba a bacer su capilla [de San Juan],

tōs yōkihtoh n San Juan: "neh ākmo niyās".

$\begin{array}{llllllll}\text { tōs } & \mathrm{y}=\overline{0}-\mathrm{k} \text {-ihtoh } & \mathrm{n} & \text { Sān } & \text { Jwān } & \text { neh } & \text { ākmo } & \text { ni-yā-s } \\ \text { entonces } & \mathrm{ya}=\text { =ST-35G.0-decir.PRT } & \text { ART } & \text { San } & \text { Juan } & \text { 1sG } & \text { no.más } & \text { 1sG.S-ir-FuT }\end{array}$

entonces San Juan ba dicho: "No me iré nunca más".

Wan entōnses yōmonōnōtskeh, kihtowah:
wan entōnses $\mathrm{y}=\overline{0}-\mathrm{m}$-mo-nō $\sim$ ōts-keh
k-ihtowa-h
y entonces ya-PST-REF-TTER Nlamar.PRT-PL.S 3SG.0-decir-PL.S
Y entonces después de que se bablaron, dicen:

"Bwēnoh, pos entōnses ākmo tiyāskeh; nikah timokāwaskeh."

bwēnoh pos entōnses ākmo ti-yā-s-keh nikān ti-mo-kāwa-s-keh
INTER pues entonces no.más
"Bueno, pues entonces no viajaremos nunca más;

Ompa ōkitimowihkeh.

ompa ō-ki-timowih-keh

ahí PST-3SG.o-bajar-PL.S

Abílo bajaron.

Ōkichīwaskiyah n tiôpantl ompa n Sisikāpah.

ō-ki-chīwa-skiya-h $\quad \mathrm{n}$ tiôpan-tl ompa $\mathrm{n}$ Sisikāpah

PST-3SG.0-hacer-CTRF-PL.S ART iglesia-ABS.SG ahí ART Cicicapa

Iban a bacer la iglesia abi en Cicicapa.

Pēroh āmo ompa n ōmochīw.

pēroh āmo ompa $\mathrm{n}$ o-mo-chīw

pero NEG ahí ART PST-REEL-hacer.PRT

Pero no se hizo abí. 
San ōkitimowihkeh parah tlatsīntlah, āxah kāmpa katki n tiôpantl San Juan Bautista Ahuacatlán.

san ō-ki-timowih-keh parah tlatsīntlan āxān kāmpa katki n tiôpan-tl Sān sólo PST-3SG.0-bajar.PRT-PL.S para abajo ahora donde estar ART iglesia-ABS.SG San

Jwān Bawtīstah Awakatlân

Juan Bautista Ahuacatlán

Sólo lo bajaron [al santo] basta abajo, donde boy está la iglesia de San Juan Bautista Abuacatán.

Entōnses ya ompa ōmokah.

entōnses ya ompa ō-mo-kāw

entonces ya ahí PST-REFL-dejar.PRT

Entonces ya se quedaron ahí.

Wan kwāndoh ōkahkokwkeh nōn īnsāntoh, entōnses, yōkahkokwkeh kwali, ākmo itik.

wan kwāndoh $\overline{0}-k$-ahkokw-keh nōn īm-sāntoh entōnses $\mathrm{y}=\overline{0}-\mathrm{k}$-ahkokw-keh

y cuando PST-3SG.o-levantar-PL.S ese 3PL.P-santo entonces ya=PST-3SG.P-levantar-PL.S

kwali ākmo itik

bueno no.más pesado

Y cuando levantaron a su santo, entonces, ya lo levantaron fácilmente, no [fue] pesado.

Yōkolīnihkeh.

$\mathrm{y}=\overline{0}-\mathrm{k}-\mathrm{olin} i \mathrm{ih}-\mathrm{keh}$

ya $=$ PST-3SG.0-mover.PRT-PL.S

Lo movieron.

Ya kwali ōkitimowihkeh parah tlatsīntlah, kāmpa katki n āxah.

ya kwali ō-ki-timowih-keh parah tlatsīntlan kāmpa katki āxān

ya bueno PST-3SG.0-bajar.PRT-PL.S para abajo donde estar ahora

Ya lo pudieron bajar para abajo, donde está boy.

Entōnses ohkôn kihtowah īch n historia.

entōnses ohkôn k-ihtowa-h $\quad \bar{i}(\mathrm{ti}) \mathrm{ch} \quad \mathrm{n} \quad$ istōryah

entonces así 3SG.0-decir-PL.S en ART historia

Entonces asi dicen en la bistoria. 
Wan nōn tyēmpoh, tikmomakah kwēntah n ōmochihchih n tiôpantl San Juan Ahuacatlán kipiya trescientos diez años.

wan nōn tyēmpoh ti-k-mo-maka-h kwēntah $n$ o-mo-chih $\sim$ chīw $n$ y ese tiempo 1PL.S-3SG.o-REEL-dar-PL.S cuenta ART PST-REEL-PIAC $\sim$ hacer.PRT ART

tiôpan-tl Sān Jwān Awakatlân ki-piya tresyēntos dyēs āño-s iglesia-ABS.SG San Juan Ahuacatlán 3sG.0-tener trescientos diez año-PL Y [sobre] ese tiempo, nos damos cuenta de que bicieron la iglesia de San Juan Abuacatlán bace 310 años.

Tōs nikah San Francisco kipiya kachi mās xiwitl.

tōs nikān Sān Fransīskoh ki-piya kachi mās xiwi-tl entonces aquí San Francisco 3sG.o-tener más más año-ABS.SG Entonces aquí San Francisco tiene más años.

Kachi mās xiwitl n kipiya nikah.

kachi mās xiwi-tl n ki-piya nikān más más año-ABS.SG ART 3SG.0-tener aquí Más años tiene aquí.

Kipiya kēmeh sē mīl îwah mākwil syēntoh wan ōmi pūwal xiwitl nikah n tiôpantl n San Francisco.

ki-piya kēmeh sē mīl ì-wān mākwil syēntoh wan ōmi pōwal 3sG.o-tener alrededor.de uno mil 3sG.P-con cinco ciento y dos veinte

xiwi-tl nikān n Sān Fransīskoh

año-ABSS.SG aquí ART San Francisco

Tiene alrededor de 1540 años la iglesia de aqui San Francisco.

Tōs kwāndoh ōwalahkeh nōn totutecos, nikah yōchānchīwtoyah n toknīwah.

tōs kwāndoh ō-walah-keh nōn totutēko-s nikah

entonces cuando PST-venir.PRT-PL.S ese totuteco-PL aquí

y=ō-chān-chīw-to-ya-h $\quad$ n to-knīw-wān

ya $=$ PST-hogar-hacer-PROG-IMPF-PL.S ART 1PL.P-hermano-POS.PL

Entonces cuado vinieron los totutecos, ya vivía la gente aquí.

Yōkatkah tlākameh.

$\mathrm{y}=\overline{0}-k a t k a-h$

tlāka-meh

ya $=$ PST-ESTAR.PRT-PL.S hombre-ABS.PL

Ya babía hombres 
Entōnses īpah tiyuweh.

entōnses i-pah ti-yowi-h

entonces 3SG.P-en 1PL.S-ir-PL.S

Entonces abi vamos.

Āxah nonoh nōn chikōmi tlākameh kinwīkah n īnsiwāwah wan $\mathrm{n}$ ompa ōkipixkeh ìmpilwah, n ompa īch nōn lugār kāmpa ōkimīxtsakwilìtoh n totutecos.

āxah nonōn nōn chikōmi tlāka-meh kim-wīka-h $n$ ìm-siwā-wān wan

ahora ese ese siete hombre-ABS.PL 3SG.0-llevar-PL.S ART 3PL.P-mujer-POS.PL y

n ompa ō-ki-piy-keh īm-pil-wān $n$ ōmpa īch nōn lugār kāmpa

ARt ahí PST-3SG.o-tener.PRT-PL.S 3SG.P-hijo-Pos.PL ART ahí en ese lugar donde

ō-kim-ix-tsakwi-li-to-h $\quad \mathrm{n} \quad$ totutēko-s

PST-3SG.0-superficie-cerrar-APL-AND.PROP.PRT-PL.S ART totuteco-PL

Ahora esos siete hombres se llevaron a sus esposas y abi tuvieron niños, abien el lugar donde obstruyeron a los totutecos.

Yōmoweyilihkeh n yēyi syēntoh xiwitl.
$\mathrm{y}=\overline{0}$-mo-weyilih-keh
n yēyi syēntoh xiwi-tl
ya $=$ PST-REFL-aumentar.PRT-PL.S ART tres ciento año-ABS.SG
Ya [sus hogares] han aumentado en estos trescientos años.

Yōmoweyilihkeh aorītah.
$\mathrm{y}=\overline{0}$-mo-weyilih-keh
aoritah
ya=PST-REFL-aumentar.PRT-PL.S ahorita
Ya ban aumentado aborita.

Yōmochih sē pwēbloh, keh āxah San Jerónimo Coaltepec.

$\begin{array}{llllll}\text { y=ō-mo-chīw } & \text { sē pwēbloh keh āxān Sān Jerônimoh Koaltepêk } \\ \text { ya=PST-REFL-hacer.PRT } & \text { uno pueblo que ahora San Jeronimo Coaltepec } \\ \text { Ya se ba hecho un pueblo, que se llama ahora San Jerónimo Coaltepec. }\end{array}$

Yeh nōn n historia.
yeh nōn $\mathrm{n}$ istōryah
3SG ese ART historia
Eso es la bistoria. 


\section{Abreviaturas}

$\begin{array}{llll}1 & \text { primera persona } & \text { NEG } & \text { negativo } \\ 2 & \text { segunda persona } & 0 & \text { objeto } \\ 3 & \text { tercera persona } & \text { OPT } & \text { optativo } \\ \text { ABS } & \text { absolutivo } & \text { P } & \text { poseedor } \\ \text { AND } & \text { andativo } & \text { PL } & \text { plural } \\ \text { APL } & \text { aplicativo } & \text { PLAC } & \text { pluraccional } \\ \text { ART } & \text { artículo } & \text { POS } & \text { poseído } \\ \text { CTRF } & \text { contrafactual } & \text { PROG } & \text { progresivo } \\ \text { DIST } & \text { distributivo } & \text { PRT } & \text { pretérito } \\ \text { FUT } & \text { futuro } & \text { PST } & \text { pasado } \\ \text { HON } & \text { honorífico } & \text { PROP } & \text { propositivo } \\ \text { IH } & \text { indefinido humano } & \text { REFL } & \text { reflexivo } \\ \text { IMPF } & \text { imperfecto } & \text { REL } & \text { pronombre relativo } \\ \text { INTERJ } & \text { interjección } & \text { S } & \text { sujeto } \\ \text { ITER } & \text { iterativo } & \text { SG } & \text { singular } \\ \text { LV } & \text { verbo ligero } & \text { VEN } & \text { venitivo }\end{array}$

Referencias

CAROCHI, Horacio

1645 Arte de la Lengua Mexicana, con la Declaración de los Adverbios della. Ciudad de México: Juan Ruiz.

EBERHARD, David M., Gary F. Simons, y Charles D. FEnNIG (eds.)

2019 Ethnologue: Languages of the World. Dallas: SIL International. Versión en línea: http://www.ethnologue.com/

GARCIA MARTínEZ, Bernardo

1987 Los pueblos de la sierra: el poder y el espacio entre los Indios del norte de Puebla hasta 1700. Ciudad de México: Colegio de México.

INALI (Instituto Nacional de Lenguas Indígenas)

2009 Catálogo de las Lenguas Indígenas Nacionales: Variantes Lingüísticas de México con sus Autodenominaciones y Referencias Geoestadísticas. Ciudad de México: Instituto Nacional de Lenguas Indígenas.

KEY, Harold, y Mary Richie DE KEY

1953 Vocabulario Mejicano de la Sierra de Zacapoaxtla, Puebla. Ciudad de México: Instituto Lingüístico de Verano.

Pharao Hansen, Magnus

2014 "The East-West Split in Nahuan Dialectology: Reviewing the Evidence and Consolidating the Grouping". Ponencia presentada en el Taller de los Amigos de las Lenguas 
Yutoaztecas, Universidad Autónoma de Nayarit, 20 de junio, 2014. https://www.researchgate.net/publication/272507445/

SANTIAGO MÉndEZ, Juan, y Mitsuya SASAKI

2016 "Rebeldia de Cuatreros en el náhuatl de San Francisco Ixquihuacan, Puebla", Tlalocan XXI: 143-166.

SASAKI, Mitsuya

2014 "A Dialectological Sketch of Ixquihuacan Nahuatl", Tokyo University Linguistic Papers (TULiP) 35: e139-170. http://hdl.handle.net/2261/56397/

2015 "A View from the Sierra: The Highland Puebla Area in Nahua Dialectology", Tokyo University Linguistic Papers (TULiP) 36: 156-165. http://hdl.handle. net/2261/58877/

TORquemaDA, Juan de

1615 Los Veynte y un Libros Rituales y Monarchia Yndiana con el Origen y Guerras de los Yndios Ococcidentales, de su Poblaciones, Descubrimiento, Conquista, Conversion y Otras Cosas Maravillosas de la Mesma Tierra, 3 volúmenes. Sevilla: Matthias Clavijo.

VALIÑas COALLA, Leopoldo José Manuel

1981 "El náhuatl de la periferia occidental y la costa del Pacífico". Tesis de licenciatura, Escuela Nacional de Antropología e Historia, Ciudad de México.

VERA Y ZURIA, Pedro

[1926] 1929 Cartas a mis Seminaristas en la Primera Visita a Pastoral de la Arquidiócesis, 2a. edición. Barcelona: Luis Gili.

Recibido: 19 de abril de 2019

Aceptado: 7 de agosto de 2019 
